International Journal of Physical Sciences and Engineering
Available online at www.sciencescholar.us
Vol. 4 No. 1, April 2020, pages: $11-20$
e-ISSN : 2550-6943, p-ISSN : 2550-6951
https://doi.org/10.29332/ijpse.v4n1.415

\title{
Potential Energy of Plant Biomass: Banana, Coconut, Cacao and Corn
}

\author{
(1) corssinati \\ Genial Belvine Epeni Tombo a, Edison Cedeño Zambrano ${ }^{b}$, Jair Loor Barreiro ${ }^{c}$, Jordi Medranda \\ Posligua $\mathrm{d}$
}

Manuscript submitted: 09 January 2020, Manuscript revised: 27 February 2020, Accepted for publication: 18 March 2010

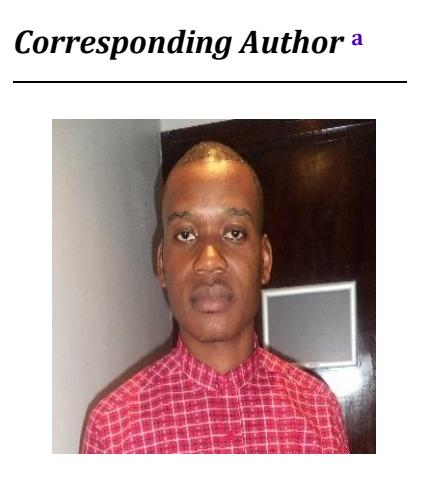

\begin{abstract}
In this document, a study was carried out on the energy potential of plant biomass in the Portoviejo canton, since climate change is not a utopia, but the reality. Throughout this study, an overview of the capacity in biomass at the national, provincial and cantonal level (Portoviejo) was presented, a study on the culture of banana, cocoa, coconut, and corn was made since it is important to know if the canton can respond to the biomass demand of the selected plants. Then the socio-economic and environmental impacts were analyzed in a general way.
\end{abstract}

\section{Keywords \\ biomass in Manabí; \\ Manabí renewable \\ energy; \\ potential energy; \\ sustainable Manabi; \\ vegetable biomass;}

International Journal of Physical Sciences and Engineering (C) 2020.

This is an open access article under the CC BY-NC-ND license

(https://creativecommons.org/licenses/by-nc-nd/4.0/).

\section{Contents}

Abstract

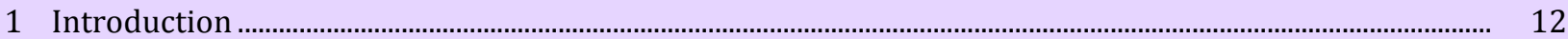

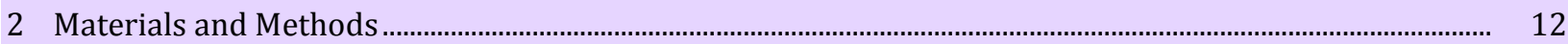

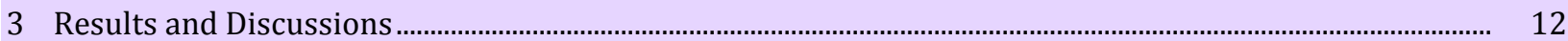

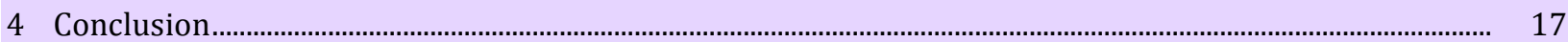

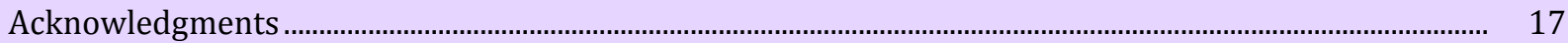

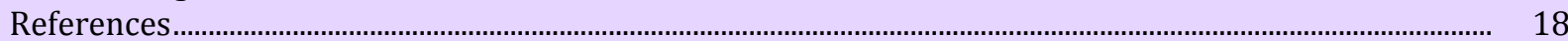

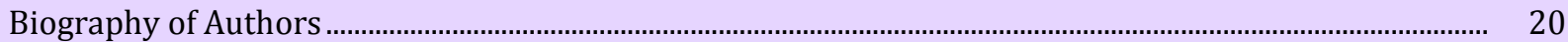

a Universidad Técnica de Manabí, Portoviejo, Manabí, Ecuador

b Universidad Técnica de Manabí, Portoviejo, Manabí, Ecuador

c Universidad Técnica de Manabí, Portoviejo, Manabí, Ecuador

d Universidad Técnica de Manabí, Portoviejo, Manabí, Ecuador 


\section{Introduction}

Current climate change it imposes us to change our way of living, acting and making decisions not only that suits us, but respects all forms of life in our environment starting with the rivers, the seas, passing through the flora and fauna, to the earth and the area So for all living beings. Concerning that vision, future engineers have the moral and ethical responsibility to establish and create norms, innovations, and projects that facilitate coexistence for each species and establish the balance of the environment (Möller \& Nix, 1976; Makogon et al., 2007; Balaras et al., 2007). The same motivation is based on this research, which aims to analyze and quantify the energy potential of biomass in the Portoviejo canton of the province of Manabí due to its diversity in agricultural production that specifically generates organic vegetable waste that is can be used to reduce the energy dependence of citizens to the source of production of the conventional electric power (heat) is produced each year some tons of co2.In this document, the research work will focus on the agricultural products of Portoviejo selected these products that are: cocoa, banana, corn, coconut. Portoviejo considered as "The city of the royal tamarinds", is geographically located at 01 degrees, 3 minutes, and 8 seconds latitude south, and 80 degrees, 27 minutes, and 2 seconds longitude west. It limits to the north, with the cantons Rocafuerte, Sucre, Junín and Bolívar; to the south, with the Canton Santa Ana; to the west with the Montecristi Canton and the Pacific Ocean and the east with the Pichincha and Santa Ana cantons. In June 1824, the was created Manabí and with it three Manabite cantons: Portoviejo, Jipijapa, and Montecristi. Portoviejo contains 9 urban parishes and 7 rural parishes (Manabí Government, 2019). Each product and its biomass yield will be developed in more detail in the following pages.

\section{Materials and Methods}

In carrying out this study on the potential of plant biomass in Portoviejo, the quantitative method was used, which allowed data to be collected on the different products that are the basis of this work, and also the qualitative methodology that served to the selection of the types of biomass to be able to carry out this investigation. The search for quality and truthful information was used through the web, based on scientific documents such as thesis (engineering, masters, doctorate), reports from organizations, national and international commissions on energy such as CONELEC, CEDA (Ecuadorian Center for Environmental Law), IDRC (International Development Research Center), OLADE among others to have a good documentation base. A visit was also made in some of the agricultural areas of the canton.

\section{Results and Discussions}

This research was carried out through the residues of Banana, corn, coconut, and cocoa, as they are the most abundant in Portoviejo, it was decided to work with these agricultural waste because it was found in different parts of the canton, in Figure 1 shows the production of agriculture in Ecuador. As can be seen, a large amount of organic waste is generated and within the canton of Portoviejo, there is a lot of bananas and corn (daily, 2017). 


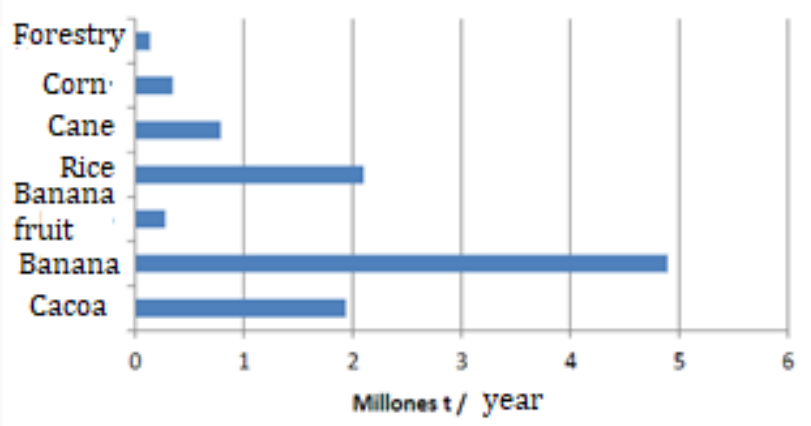

Figure1. Production of agricultural waste in Ecuador (Roman, 2015)

This high amount of waste produced, allows the opening of an interesting field of exploitation of them, through their energy conversion to electricity, heat, and production of biofuels of high added value. All these organic polymers are made up of carbon, oxygen, hydrogen, nitrogen, sulfur atoms among others. From this point of view, biomass has a percentage composition as shown in table 1.

Table 1

Biomass element composition (Pérez, 2011)

\begin{tabular}{ll}
\hline Element & Percentage by weight on a dry basis (\%) \\
\hline Carbon (C) & $30-60$ \\
Oxygen (O) & $30-40$ \\
Hydrogen (H) & $5-6$ \\
Nitrogen (N), Sulfur (S), Chlorine (Cl) & $<1 \%$ \\
\hline
\end{tabular}

Portoviejo has an annual average solar radiation of 4,850kWh / $\mathrm{m}^{2}$ day (Rodríguez \& Vázquez, 2017), (Rodríguez \& Vázquez, 2018), which favors the agriculture of banana, coconut, corn, and cocoa. The first product that was studied in this research was the banana. The largest production area of this mustard is the province of Manabí with 52612 ha, currently a total of 144981 ha of plantain are reported in the country, of which 86712 ha, are under the monoculture system and 58269 ha are associated with Other crops For the sowing of new plantations, strains should be selected from small grandfathers or hills of $1.60-1.80 \mathrm{~m}$, cleaning, and disinfection with insecticides furadan $3 \mathrm{~F}(200 \mathrm{~mL} / 100 \mathrm{~L}$ of water), furadan $4 \mathrm{~F}(150 \mathrm{~mL} / 100 \mathrm{~L}$ of water), or $30 \mathrm{~g}$ of $10 \% \mathrm{G}$ insecticide-nematicide (Furadan, Counter, Mocap, etc.), applying $15 \mathrm{~g}$ to the bottom of the hole and $15 \mathrm{~g}$ as the strain is buried. In Portoviejo it is present with not very large plantations and with an area of $1,031.85$ hectares that represents $1.07 \%$ of the cantonal surface; its spatial location is in the central part of the canton generally close to the main roads. Banana crops are mainly distributed in the parish of Abdón Calderón; and in the parish of Portoviejo north of it and south in the valley (SENPLADES, 2012). The maintenance in the useful life of the productive units for the control of nematodes in established plantations is recommended the use of the products terbufos, fenamifos, ethoprop, and carbofuran in doses of $3 \mathrm{~g}$ ia/plant and oxamyl 2,4 mL/plant.

Nematicides should be applied based on the population levels obtained after making the nematological diagnosis. The diagnoses are more representative when sampling is done in front of the child in a succession of $1.50-2.0 \mathrm{~m}$ high. This practice prevents the deterioration of the roots and consequently, the overturning of the productive units. It has been determined that nematodes reduce banana yields by 30 percent. The cultivation of bananas and their collateral industries, generate employment for more than one million families, this represents about 2.5 million people nationwide, which in percentage equals approximately $17 \%$ of the current population, which depend on a or another form of the banana industry (Tokimoto et al., 2005; SuárezGarcia et al., 2002; Valdrighi et al., 1996). The Ecuadorian banana market is diversified, exporting the fruit to the European Union (42\%) USA (21\%) Russia (20\%), Southern Cone $(6 \%)$ as main markets and $11 \%$ to

Tombo, G. B. E., Zambrano, E. C., Barreiro, J. L., \& Posligua, J. M. (2020). Potential energy of plant biomass: banana, coconut, cacao and corn. International Journal of Physical Sciences and Engineering, 4(1), 11-20. 
marginal markets (Middle East, Eastern Europe, North Africa, and Asia) (Cedeño, 2019). In figure 2, part of the banana residuals is shown.

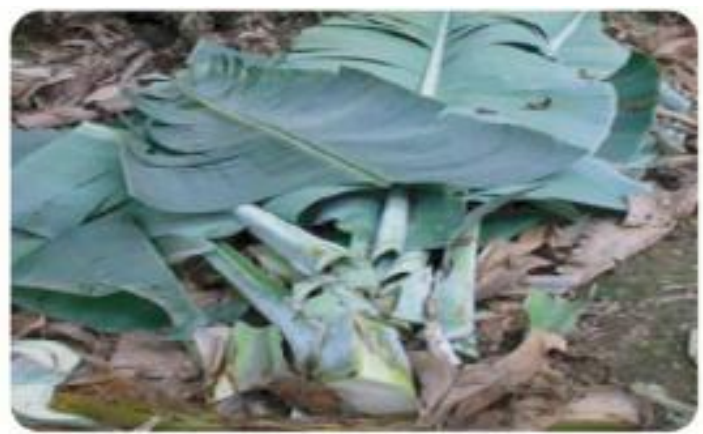

Figure 2. The banana residue (agro)

In the second place was the production of corn and its energy potential. In Portoviejo the main crop is usually hard corn, it is used for the production of balanced, there is a cultivated area of 9210.61 ha and it is mostly located in the central and southwest part of the canton, in the latter in the Valley from Portoviejo. It should be noted that in areas where there is an irrigation presence, they cultivate more than one cycle. This product occupies $9.56 \%$ of the total cantonal area. The yield of corn at the national level for the year 2010 was 2.77 MT/ ha (National Secretary of Planning and Development, 2012). During 2017, about 1.2 million tons of corn were produced in Ecuador on the more than 200,000 hectares planted in the country, according to statistics from the Tierra Fertile Corporation, in the Ventanas canton, Los Ríos. El Oro was the province that exceeded the national average with $7.63 \mathrm{t}$ / ha, while the lowest was Guayas with $4.50 \mathrm{t}$ / ha (leading magazine, 2018). Three (3) years ago in 2014 precisely the production of corn was 1.54 million tons, which represented $0.15 \%$ of world production (Baca, 2016). The province of Manabí represents 22\% of the national production, the majority of which is produced in the Jipijapa canton. In 2016, a training was held in Moquimble, Colón parish of the Portoviejo canton; at the Portoviejo Experimental Station facilities. In the mentioned sites, activity was developed on estimating the yield and its losses due to attack of diseases in the cultivation of hard corn; harvest exercises (defoliate and quantify); observation of plants with late wilt and also practice was carried out to know field weight, percentage of shelling of harvested ears, the weight of cob, weight of grain, percentage of moisture of the grain, among other topics (National Institute of Agricultural Research, 2016), reference in the figure.

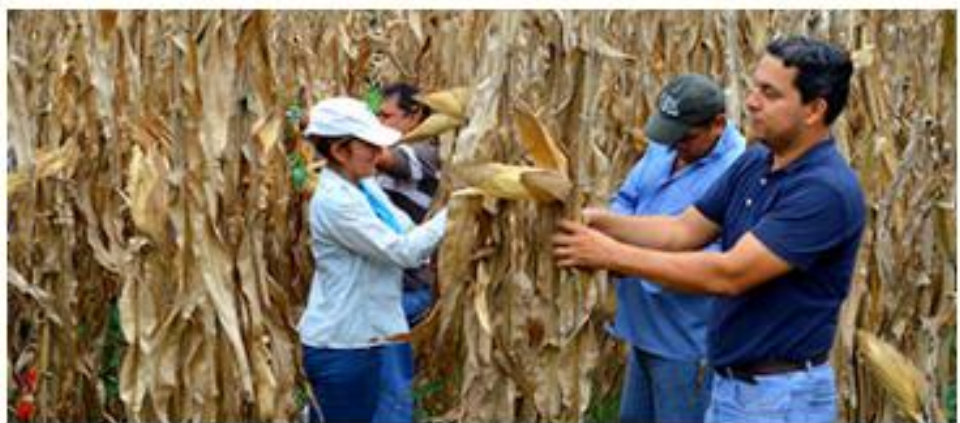

Figure 3. Portoviejo experimental station

In 2010 the main cocoa-producing provinces in Ecuador were Manabí with 22\% of the national area followed by Los Ríos with $21.33 \%$ and Guayas with $20.67 \%$ (table 1). Regarding yields: Guayas was the province that had the highest yield with $0.66 \mathrm{t} / \mathrm{ha}$, Los Ríos $0.47 \mathrm{t} /$ ha and Manabí the lowest $0.27 \mathrm{t}$ / ha (Pérez, 2011). At present, in Portoviejo, cocoa is the second most important crop in the canton; the majority of cocoa plantations are mainly represented by national cocoa. Similarly, branch cocoa has been identified to a lesser extent and spatially dispersed. These crops have an extension of 2,636.43 ha, and are located near the main 
roads; located mainly in the parishes of Portoviejo, Abdón Calderón, Rio Chico and Alajuela (Posso et al., 2019; Salgado et al., 2020).

Cocoa production in the Portoviejo canton has a yield of $0.4 \mathrm{MT} /$ ha per year, the area of cocoa cultivation in monoculture in Portoviejo extends over 4,498 ha (illustration 5) (INIAP, 2010). This states that it is within the average to the national coffee yield figures, which range from 0.27 to $0.48 \mathrm{MT} /$ ha in a period from 2000 to 2010. Table 1 shows the area and yield planted by province

Table 1

Planted area and yield by province

\begin{tabular}{lll}
\hline Provinces & Planted Area (ha) & Yield (t / ha) \\
\hline Manabi & 108649 & 0.27 \\
Los Ríos & 104788 & 0.47 \\
Guayas & 102104 & 0.66 \\
Esmeraldas & 56739 & 0.41 \\
El Oro & 18092 & 0.42 \\
Santo Domingo & 17538 & 0.43 \\
Cotopaxi & 14872 & 0.32 \\
National total & 491221 & 0.43 \\
\hline
\end{tabular}

Table 2 shows the percentage of the farm dedicated to the sowing of cocoa, in the different strata. Fortaleza del Valle Corporation, Manabí. 2011; in which we can appreciate the different sizes of the farms with the percentage of the farm planted with cocoa, the number of farmers concerning each size of farm (Fernandez, 2011).

Table 2

The percentage of the farm dedicated to planting cocoa in different strata

\begin{tabular}{llll}
\hline Stratum & Farmers (\%) & Number of farmers & $\begin{array}{l}\text { Percentage of the farm } \\
\text { planted with cocoa }\end{array}$ \\
\hline Large 10.10onwards & 50.00 & 1 & 8,00 \\
& 50.00 & 1 & 73.33 \\
Medium 4.10 to 10 h at & 53.33 & 8 & 100.00 \\
& 20.00 & 3 & $15.00-16.70$ \\
Small 0.30 to 4ha & 6.66 & 1 & 85.71 \\
& 6.66 & 1 & 45,00 \\
& 6.66 & 1 & 33.33 \\
& 8.74 & 1 & 7.90 \\
& 14.29 & 11 & 100.00 \\
& 10.31 & 18 & $75.00-86.00$ \\
& 10.31 & 13 & $50.00-66.70$ \\
& & 13 & $25.00-44.40$ \\
\hline
\end{tabular}

Figure 4, show how the cocoa is dried (A) and in the peanut plantations in (B). In figure 4, showing how cocoa is dried (A) and in cocoa plantations in (B), it is good to reflect that there are better ways to dry coffee and cocoa, using solar dryers that give quality to the product (Zambrano et al., 2018), these practices can generate throughout the province of Manabí, as they are high producers of Cacao, Coffee, peanuts and other beans.

Tombo, G. B. E., Zambrano, E. C., Barreiro, J. L., \& Posligua, J. M. (2020). Potential energy of plant biomass: banana, coconut, cacao and corn. International Journal of Physical Sciences and Engineering, 4(1), 11-20. 


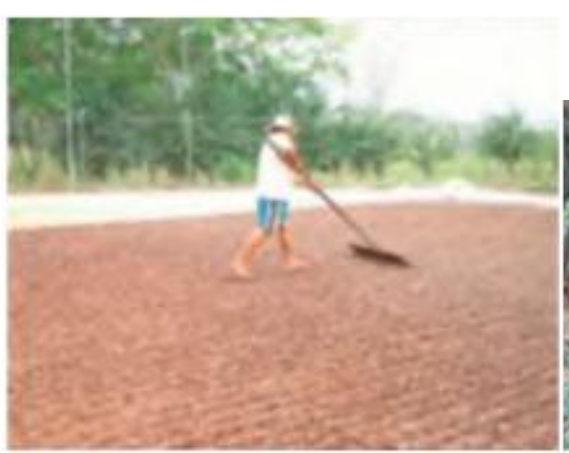

A

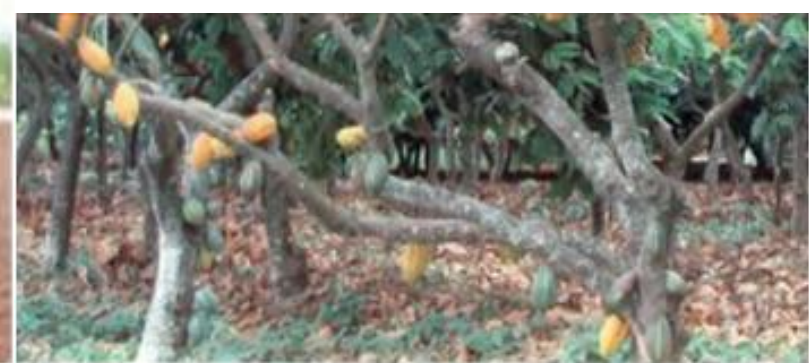

B

Figure 4. Drying and growing cocoa

The coconut, where it has the highest production in the province of Esmeraldas, with many hectares that reach $77.26 \%$ of the national total, followed by Manabí, with $18.72 \%$. In that province there are 1489 hectares of coconut plantations (Lideres, 2017), coconut plantations are located in the northern part of the canton and along the main roads, focusing on the Rio Chico and Portoviejo parishes in areas that border the Rocafuerte canton. An area of 547.63 ha has been identified, which represents $0.57 \%$ of the total cantonal territory.

\section{Socio-economic impact}

In recent years, Ecuador has incorporated cogeneration systems using biomass, excess electrical energy is delivered to the national energy network. Until now the main crop that has been used for the generation of electrical energy is sugar cane, in the mills that the country possesses. They include Eco electric (36.5 MW), San Carlos (35 MW) and Escudos (29.8 MW). This represents 1.74\% of the electricity produced in Ecuador in 2016 (Guerrero et al., 2016).

With the potential of the four cultures, a biomass plant can be implemented in Portoviejo, due to the large amount of organic waste produced by bananas, cocoa, coconut, and corn. Being possible because all these crops are collected at the same time, allowing the availability of biomass, being able to reduce considerably the dependence of the citizens to the conventional energy source, reducing the pollution produced (Hussein, 2015; Gamez et al., 2017).

At a national level, the income generated by the banana activity represents $3.84 \%$ of the total GDP; $50 \%$ of agricultural GDP and 20\% of the country's private exports, Banana cultivation and its collateral industries, generate employment for more than one million families, this represents about 2.5 million people, which in the percentage they are equivalent to approximately $17 \%$ of the current population, which depend in one way or another on the banana industry (Cedeño, 2018).

In Portoviejo, more than 1000 people live from that culture and with the implementation of that plant, production will continue and grow concerning the growth of energetic production. Similarly, many jobs could be generated (Gomelsky, 2013), for the operation of the plant and in the agricultural sector.

\section{Environmental}

Impact The direct impact is the considerable reduction of $\mathrm{CO}_{2}$ produced by the conventional source and other linked gases, it contributes to the reduction of the greenhouse effect and the possible acid rain, deforestation is also reduced, and to take advantage of the banana, coconut residues, cocoa and corn creating an energetic culture 


\section{Conclusion}

In the canton, Portoviejo has a large production of corn and plantain that is found in rural parishes and at the time of making their crops vote the corn leaf or burn it, also wastes the maize rachis, just as with bananas, this waste can contribute to the generation of electricity, bioethanol, and biodiesel because they are rural areas that currently have poor energy quality. Biodiesel can be produced in the canton through the use of corn, by extracting vegetable oil, with a yield of $145 \mathrm{~kg}$ of oil $/ \mathrm{ha}$. The potential of biomass through banana residues could cover a high demand for electricity in the canton and electricity generation from lignocellulosic waste such as the stem and leaves of the plant, these would contribute to the development of bioenergy and the economy. Using these residuals, the canton could become an energy sustainable zone.

\section{Acknowledgments}

This work was carried out through the support of GOD, our respective family, and also the provision of our teachers, in particular Dr. Maria, for her availability, motivation and the fact of believing in us.

Tombo, G. B. E., Zambrano, E. C., Barreiro, J. L., \& Posligua, J. M. (2020). Potential energy of plant biomass: banana, coconut, cacao and corn. International Journal of Physical Sciences and Engineering, 4(1), 11-20. 


\section{References}

Baca, L.A. (2016). Dissertation prior to obtaining the title of Economist. Yellow corn production in Ecuador and its relationship, 28. Quito, Ecuador: Pontifical Catholic University of Ecuador.

Balaras, C. A., Gaglia, A. G., Georgopoulou, E., Mirasgedis, S., Sarafidis, Y., \& Lalas, D. P. (2007). European residential buildings and empirical assessment of the Hellenic building stock, energy consumption, emissions and potential energy savings. Building and environment, 42(3), 1298-1314. https://doi.org/10.1016/j.buildenv.2005.11.001

Cedeño, I.A. (2019). Banana, banana and other musaceae. Récupéré sur National Institute of Agricultural

Cedeño, I.A. (sd). (2018). Banana, banana and other musaceae.

Fernandez, P.A.M. (2011). Determination of the adoption of cocoa genotypes and its technological components generated by iniap, in cocoa zones. 44. Sangolquí, Ecuador.

Gamez, M. R., Perez, A. V., Sera, A. S., \& Ronquillo, Z. M. (2017). Renewable energy sources and local development. International Journal of Social Sciences and Humanities, 1(2), 10-19. https://doi.org/10.29332/ijssh.v1n2.31

Gomelsky, R. (2013). Sustainable energy for all: Rapid assessment and analysis of gaps Ecuador. MEER, IDB and UNDP 2013.

Guerrero, A. B., Aguado, P. L., Sánchez, J., \& Curt, M. D. (2016). GIS-based assessment of banana residual biomass potential for ethanol production and power generation: a case study. Waste and biomass valorization, 7(2), 405-415. https://doi.org/10.1007/s12649-015-9455-3

Hussein, A. K. (2015). Applications of nanotechnology in renewable energies-A comprehensive overview and understanding. Renewable and Sustainable Energy Reviews, 42, 460-476. https://doi.org/10.1016/j.rser.2014.10.027

INIAP. (2010). Management of cocoa cultivation technician. 1. Portoviejo.

Lideres (2017). Esmeraldas concentrates coconut palm.

Magazine leaders. (2018). Leaders Récupéré

Makogon, Y. F., Holditch, S. A., \& Makogon, T. Y. (2007). Natural gas-hydrates-A potential energy source for the 21st Century. Journal of petroleum science and engineering, 56(1-3), 14-31. https://doi.org/10.1016/j.petrol.2005.10.009

Möller, P., \& Nix, J. R. (1976). Macroscopic potential-energy surfaces for symmetric fission and heavy-ion reactions. Nuclear Physics A, 272(2), 502-532. https://doi.org/10.1016/0375-9474(76)90345-6

National Institute of Agricultural Research. (2016). Récupéré sur INIAP: http://www.iniap.gob.ec/pruebav3/iniap-capacita-en-manejo-del-cultivo-de-maiz-en-portoviejo/

National Secretary of Planning and Development. (2012). Portoviejo canton technical report "geoinformation generation for the management of Porthoviejo.

Pérez, M.A. (2011). Determination of the Adoption of Cocoa Genotypes and their Technological Components Generated by Iniap, in Manabí Representative Cocoa Zones. Research Project Report Presented as Partial Requirement to Opt for the Title of Agricultural Engineer, 22. Sangolquí, Ecuador: Sangolquí Army Polytechnic School.

Posso, F., Siguencia, J., \& Narváez, R. (2019). Residual biomass-based hydrogen production: Potential and possible uses in Ecuador. International Journal of Hydrogen Energy. https://doi.org/10.1016/j.ijhydene.2019.09.235

Rodriguez, A. C. Z., Gamez, M. R., \& Faure, L. G. (2018). Design, construction, and energy of sustainable solar dryers in Jipijapa Canton. International Journal of Physical Sciences and Engineering,2(2), 88-100. https://doi.org/10.29332/ijpse.v2n2.170

Rodríguez, M. \& Vázquez, A. (2017). Solar Potential and Distributed Generation in the Province of Manabí in Ecuador. 2 (2), 4. Manabi, Ecuador: Riemat Julio Magazine.

Rodríguez, M., \& Vázquez, A. (2018). La energía fotovoltaica en la provincia de Manabí. Ediciones UTMUniversidad Técnica de Manabí. ISBN: 978-9942-948-20-5.

Roman, L. (2015). Energy by Biomass. Mexico: Investigating the world.

Salgado, M. A. H., Tarelho, L. A., Rivadeneira, D., Ramírez, V., \& Sinche, D. (2020). Energetic valorization of the residual biomass produced during Jatropha curcas oil extraction. Renewable Energy, 146, 1640-1648. https://doi.org/10.1016/j.renene.2019.07.154 
Senplad (2012). Production system:_Generation of geoinformation for the management of the territory at national level. PortoviejO.

Suárez-Garcıa, F., Martınez-Alonso, A., Llorente, M. F., \& Tascón, J. M. D. (2002). Inorganic matter characterization in vegetable biomass feedstocks. Fuel, 81(9), 1161-1169. https://doi.org/10.1016/S00162361(02)00026-1

Tokimoto, T., Kawasaki, N., Nakamura, T., Akutagawa, J., \& Tanada, S. (2005). Removal of lead ions in drinking water by coffee grounds as vegetable biomass. Journal of Colloid and interface Science, 281(1), 56-61. https://doi.org/10.1016/j.jcis.2004.08.083

Valdrighi, M. M., Pera, A., Agnolucci, M., Frassinetti, S., Lunardi, D., \& Vallini, G. (1996). Effects of compostderived humic acids on vegetable biomass production and microbial growth within a plant (Cichorium intybus)-soil system: a comparative study. Agriculture, Ecosystems \& Environment, 58(2-3), 133-144. https://doi.org/10.1016/0167-8809(96)01031-6

Tombo, G. B. E., Zambrano, E. C., Barreiro, J. L., \& Posligua, J. M. (2020). Potential energy of plant biomass: banana, coconut, cacao and corn. International Journal of Physical Sciences and Engineering, 4(1), 11-20. 


\section{Biography of Authors}

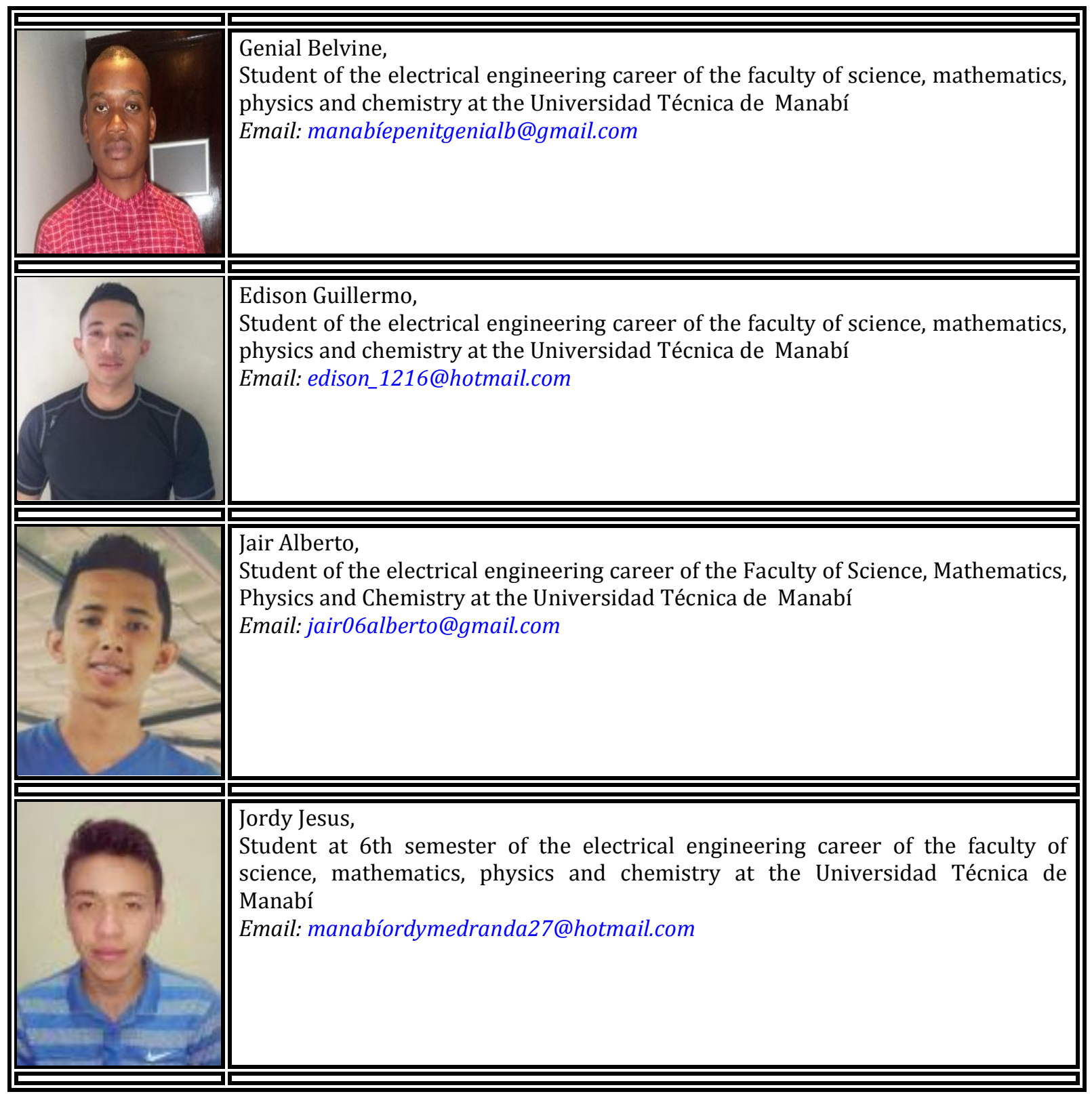

